\title{
A Revista Brasileira de Educação e a difusão da pesquisa educacional (2007-2011)
}

CARLOS EDUARDO VIEIRA

Universidade Federal do Paraná

SANDRA ZÁKIA SOUSA

Universidade Cidade de São Paulo

Universidade de São Paulo

Este texto apresenta um mapeamento do que se vem divulgando pela Revista Brasileira de Educação (RBE) no período de 2007 a 2011, em que foram publicados 15 fascísculos, do número 34 ao $48 .{ }^{1}$ Não se pretende uma apreciação qualitativa da produção. Os dados aqui apresentados são ilustrativos do que vem sendo produzido na área da educação e divulgado pela $R B E$, destacando-se referências sobre a sua circulação, as temáticas privilegiadas e o lócus da produção.

Sistematizar e publicizar esses dados tem como principal motivação o fato de o periódico ser editado pela Associação Nacional de Pós-Graduação e Pesquisa em Educação (ANPEd), o que o leva a constituir-se em espaço privilegiado de difusão da produção científica da área, imprimindo-lhe um caráter plural, pois a associação congrega pesquisadores de âmbito nacional e internacional, que investigam diferentes temáticas, tomando-se por base enfoques teórico-metodológicos distintos.

1 A análise dos fascículos de número zero a número 34 (jan./abr.2007) pode ser encontrada em Fávero e Barreiros (2007). 
Buscar pistas sobre como essa característica se traduz no que vem sendo divulgado no periódico é um dos propósitos deste estudo, podendo vir a subsidiar debates acerca do papel que a $R B E$ vem desempenhando no contexto da associação e da área da educação e que extrapolam o âmbito dos editores que mais diretamente se envolvem com sua produção e venham a contribuir para o seu contínuo aprimoramento. Além disso, espera-se também que se possa estimular uma discussão que ultrapasse aspectos específicos da revista, que aborde questões sobre o que se vem produzindo na área da educação e seu processo de divulgação em periódicos científicos.

Um dos propósitos da ANPEd é colaborar com o desenvolvimento e a qualificação da pós-graduação e da pesquisa na área de educação no Brasil, promovendo, entre outras iniciativas, espaços de disseminação e análise do conhecimento produzido, contando com a $R B E$ como um desses espaços. ${ }^{2}$ Daí ser relevante a busca de evidências sobre a sua configuração, aspecto central deste artigo.

O mapeamento de informações reunido e socializado, embora não exaustivo quanto às dimensões de análise possíveis, é ilustrativo do perfil da revista, em particular nos anos recentes, e está organizado em três seções. À apresentação sucinta do escopo da $R B E$ e do processo de gestão editorial vigente segue-se a indicação da procedência dos artigos e dos temas e assuntos que têm sido divulgados com maior frequência e o registro de informações de acesso ao periódico, tendo como fonte dados estatísticos do Scientific Electronic Library Online (SciELO) e da Red de Revistas Científicas de América Latina y el Caribe, España y Portugal (Redalyc). O texto é finalizado com a apresentação de desafios e perspectivas que se colocam para os periódicos científicos na atualidade, com os quais a revista se soma no processo de veiculação da produção intelectual da área de educação e, eventualmente, de áreas congêneres.

\section{SOBRE A REVISTA}

A $R B E$ tem por objetivo publicar artigos inéditos de autores brasileiros e estrangeiros que tratem de educação, resultantes de estudos teóricos, pesquisas, reflexões sobre práticas e discussões polêmicas. Publica também documentos, resenhas e notas de leitura. Na seção Documentos, divulga textos coletivos elaborados pelos componentes da diretoria e de outras pessoas ligadas à ANPEd ou por associações afins, bem como documentos emanados de órgãos governamentais e que abordem questões de interesse para a área educacional.

2 Para compreender as origens, desenvolvimento, expansão e afirmação da revista, além do artigo de Alceu Ravanello Ferraro (2005), os interessados podem ler neste número da $R B E$ o texto de Lucídio Bianchetti, elaborado com base em entrevistas e depoimentos de anpedianos históricos e outros protagonistas que foram responsáveis e estiveram diretamente relacionados com a revista desde sua gênese. 
A partir de dezembro de 2008, a organização e o funcionamento da $R B E$ são regulamentados por resolução da diretoria da associação. ${ }^{3}$ Essa resolução define, entre outros aspectos, que a produção da revista é de responsabilidade de um editor em colaboração com uma comissão editorial, cujos membros são escolhidos entre os associados da ANPEd e nomeados pela diretoria da associação por um período de três anos, sendo permitida uma recondução. Na produção da revista, conta-se, conforme resolução, com um(a) secretário(a) de redação. Também se prevê a colaboração, no trabalho de editoria, de um conselho editorial e de pareceristas ad hoc.

Algumas modificações vêm sendo introduzidas na sistemática de trabalho da $R B E$ desde meados de 2010 , cabendo destacar a recepção e processamento dos artigos on-line, por meio do SciELO, e a implantação da secretaria da revista na sede da ANPEd, o que representou desafios para a organização de novos procedimentos de editoração da revista, ao mesmo tempo em que garantiu registro sistematizado de todos os passos e encaminhamentos de sua produção na esfera da associação.

A revista recebe artigos originados de demanda direta, submetidos à avaliação por meio do SciELO, além de textos oriundos das reuniões anuais (RA) da associação, indicados pelo Comitê Científico (CC) e, no caso de trabalhos encomendados, pelos grupos de trabalho (GT), bem como contribuições de pesquisadores convidados para participar nas reuniões como conferencistas ou componentes de mesas-redondas. Artigos procedentes de convites são em número reduzido, o que usualmente ocorre em relação a pesquisadores estrangeiros, aceitando-se textos traduzidos que tragam contribuições relevantes para a área.

A produção da $R B E$ dá-se por meio de um trabalho coletivo, com participação de todos os membros da comissão nas decisões a ela concernentes. Os textos submetidos à avaliação são distribuídos pelo editor responsável e pela secretaria da revista entre os membros da comissão, que se responsabilizam - após uma primeira leitura para verificação da pertinência do texto em relação ao escopo e linha editorial da revista - pelo seu encaminhamento para, no mínimo, dois avaliadores e pela emissão de parecer final. Esse parecer, com os argumentos consolidados, registra a decisão de: recomendar o artigo para publicação, condicionar a eventual publicação a alterações ou rejeitar. Cabe ao editor tomar a decisão de aceitar ou não o texto submetido à avaliação para publicação com base nas recomendações e justificativas dos pareceristas. O parecer final sobre o artigo é enviado ao autor para que possa conhecer a avaliação feita e, se for o caso, responder às críticas e/ou atender às sugestões de modificações do texto. A identidade dos pareceristas é mantida em sigilo, assim como a dos autores quando do encaminhamento do artigo para parecer.

Os artigos são analisados tomando-se por critérios básicos sua contribuição à educação e à linha editorial da revista, a originalidade do tema ou do tratamento dado a ele, assim como a consistência e o rigor da abordagem teórico-metodológica.

3 Disponível em: <http://www.anped.org.br/>. Acesso em: 29 abr. 2011. 
Na produção de cada número, o editor responsável conta com a colaboração mais próxima de um membro da comissão editorial, que acompanha diretamente as diversas fases de trabalho, desde a organização do número até as atividades sob responsabilidade da editora, de revisão dos textos, diagramação e impressão.

É grande a quantidade de textos submetidos à avaliação, aspecto que pode estar também relacionado à classificação da $R B E$ como $\mathrm{A} 1$ internacional no Qualis. ${ }^{4}$ No período de 13 de maio a 31 de dezembro de 2010, foram submetidos à avaliação 253 artigos, além de resenhas e notas de leitura. No ano de 2011, foram 624 artigos aos quais se somam pouco mais de 40 resenhas e ensaios endereçados à seção Espaço Aberto e Notas de Leitura. Nesses anos, chama a atenção o número elevado de artigos recusados, considerando o não atendimento aos critérios estabelecidos pela revista quanto à forma, sendo 100 no ano de 2010 e 379 em 2011. Essa constatação já havia sido registrada por Fávero e Barreiros (2007), ao comentarem que, à época, vários artigos eram recusados "pela inadequação da forma (textos curtos, com aparência de trabalhos apresentados em disciplinas, formatados como relatórios de pesquisa, meros levantamentos quantitativos etc.) ou porque evidentemente não se enquadram no perfil da publicação", características essas que são ainda presentes em muitos dos textos submetidos à revista. Além disso, há que se registrar que dos muitos artigos que são submetidos à avaliação são aprovados aproximadamente $25 \%$, o que remete à discussão da qualidade do que se vem produzindo ${ }^{5}$ na área.

A intensa busca por publicação, especialmente de docentes e discentes vinculados à pós-graduação, submetendo à apreciação artigos que não atendem aos critérios comumente estabelecidos pelos periódicos já consolidados, tem sido crescente, se não por outras razões, em decorrência da sistemática indutiva de avaliação da pós-graduação implementada pela Coordenação de Aperfeiçoamento de Pessoal de Nivel Superior (CAPES), que tem nesse quesito o elemento de maior peso na avaliação dos programas.

No caso da $R B E$, mesmo considerando o número elevado de artigos não aceitos para publicação, são muitos os textos aprovados em relação à capacidade de seu acolhimento nos três números editados a cada ano, o que evidencia a oportunidade de se ampliar o número de fascículos por ano, para o que se faz necessário a viabilização de uma infraestrutura de editoração compatível.

4 Qualis é o conjunto de procedimentos utilizados pela Coordenação de Aperfeiçoamento de Pessoal de Nível Superior (CAPES) para estratificação da qualidade da produção intelectual dos programas de pós-graduação, sendo A1 o indicativo mais elevado. Como resultado, disponibiliza uma lista com a classificação dos veículos utilizados pelos programas de pós-graduação para a divulgação da sua produção. Disponível em: $<$ http://www.capes.gov.br>. Acesso em: 12 maio 2012.

5 O elevado número de artigos não aceitos para publicação é uma realidade não exclusiva da $R B E$ ou da área da educação; em eventos promovidos pela Associação Brasileira de Editores Científicos (ABEC), dos quais temos participado, tem sido possível constatar que esse fato é comum entre os periódicos dos diversos campos do conhecimento. 
Fica, entretanto, o registro da oportunidade do debate entre editores envolvidos com a produção de periódicos acadêmicos sobre a questão da qualidade, que envolve desde aspectos de aportes operacionais até a necessária relação entre produção e difusão do conhecimento. $\mathrm{Na}$ área da educação, assim como nas diversas áreas do conhecimento, a discussão da qualidade dos periódicos que veiculam a produção científica tem sido crescente, abarcando também a constatação de que uma profusão de títulos é criada, ${ }^{6}$ muitas vezes, sem as necessárias condições de editoração, o que tende a resultar periodicidade irregular nas publicações, restrita distribuição, lacunas no atendimento aos requisitos de normalização dos artigos e dificuldade de sua indexação em bases de dados. A essa constatação associa-se o debate sobre o impacto ${ }^{7}$ do que se tem divulgado, aspecto esse que merece um tratamento específico quando se trata da produção da área da educação, o que nos furtaremos a comentar neste artigo para evitar abordar de modo simplificado uma questão complexa, que remete, entre outros tantos elementos, à análise da qualidade dos próprios artigos que são veiculados. Acreditamos que o Fórum de Editores de Periódicos da Área da Educação, criado em abril de 2012 no âmbito da ANPEd, se constituirá em um espaço para o acolhimento desse debate.

\section{MAPEAMENTO DA PRODUÇÃO DIVULGADA: TENDÊNCIAS}

A análise aqui apresentada considerou os textos publicados na seção Artigos, entre os anos de 2007 e 2011, e levou em conta os seguintes aspectos: autoria, vínculo institucional, título dos artigos, as três primeiras palavras-chave e o resumo dos textos. Problematizamos os dados inerentes aos 109 artigos selecionados com base em um conjunto de aspectos, tais como: gênero; concentrações internacionais, regionais, estaduais e institucionais; e, por fim, temas priorizados. Buscamos também dados disponibilizados pelo SciELO, tais como: fator de impacto, número de acessos aos artigos da $R B E$ e temas privilegiados nos dez artigos mais acessados da revista. À exceção do fator de impacto, que incide sobre os últimos três anos (2009 a 2011), e do número de acessos à $R B E$ na plataforma SciELO, todos os outros dados foram coletados levando em consideração o período entre os anos de 2007 e 2011, ou seja, os últimos cinco anos de publicação da $R B E$.

O primeiro cenário em destaque foi a distribuição dos artigos considerando a categoria gênero (Figura 1$){ }^{8}$

6 A listagem do Qualis/CAPES/Educação divulgada pela área de educação em março de 2012 é ilustrativa dessa afirmação. Disponível em: <http://qualis.capes.gov.br>. Acesso em: 29 abr. 2011.

7 Os artigos de Strehl (2005) e Thomaz, Assad e Moreira (2011) trazem informações e procedimentos que vêm sendo utilizados em diversas áreas de conhecimento para avaliação de impacto da produção científica veiculada em periódicos.

$8 \mathrm{Na}$ análise desses dados, é importante destacar que consideramos as coautorias; logo, a quantidade de autores supera o número de artigos analisados. 


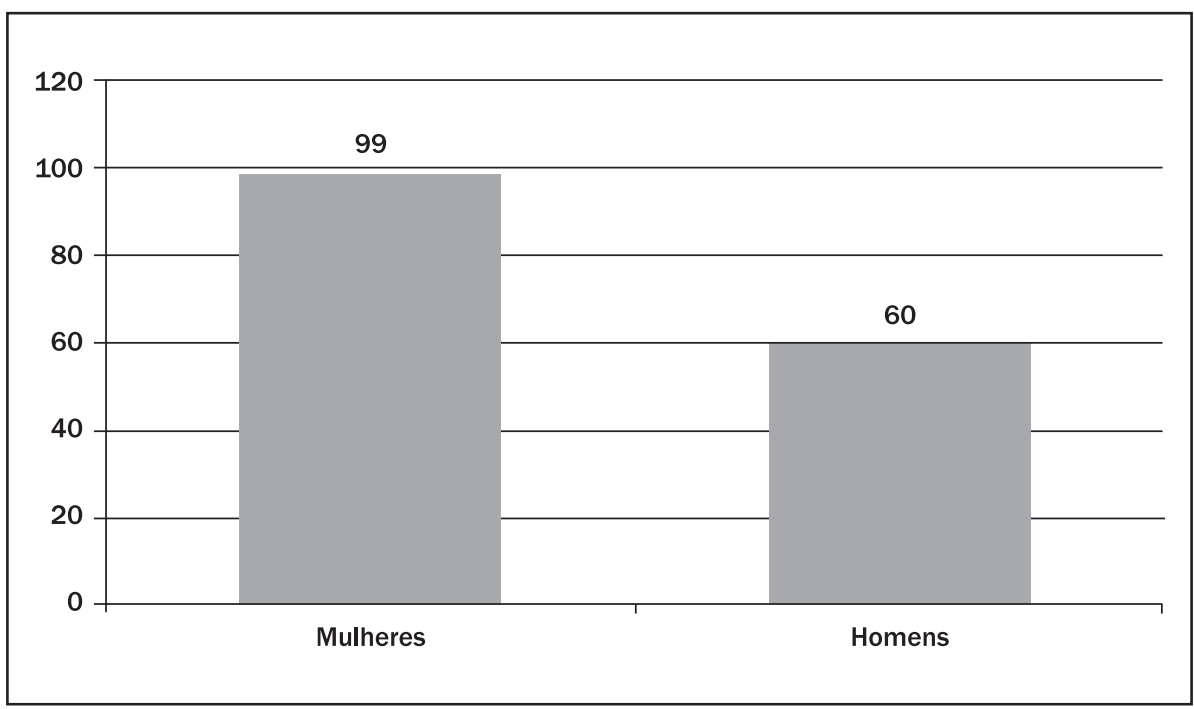

Figura 1- Distribuição em números absolutos da autoria dos artigos considerando a categoria gênero. Fonte: RBE-SciELO (2007-2011).

Elaboração dos autores.

A presença majoritária das mulheres, com $62 \%$, não representa novidade na área, considerando a histórica concentração do trabalho feminino no campo educacional, que se reflete também no plano específico do mundo acadêmico. Talvez, no caso desses números, seria interessante uma comparação com períodos anteriores para analisar possíveis oscilações nessas proporções. Porém, como essa possibilidade não se apresenta para este momento, cabe apenas destacar a forte presença das mulheres na $R B E$.

O segundo aspecto analisado foi a distribuição dos artigos por regiões do país. Esses dados confirmam uma realidade bastante conhecida da sociedade brasileira, que principia pela distribuição desigual da renda e culmina com as diferenças em acesso e qualidade das escolas públicas nas diferentes regiões do país. Esse fato atinge também o campo acadêmico, resultando na distribuição desigual da pesquisa e da socialização de seus resultados em forma de artigos entre as diferentes regiões do país. ${ }^{9}$

9 Nos dados referentes à distribuição regional, estadual e institucional, assim como na distribuição das frequências da categoria gênero, consideramos as coautorias, computando duplamente os artigos de autores e coautores situados em diferentes regiões, estados ou instituições universitárias brasileiras. 


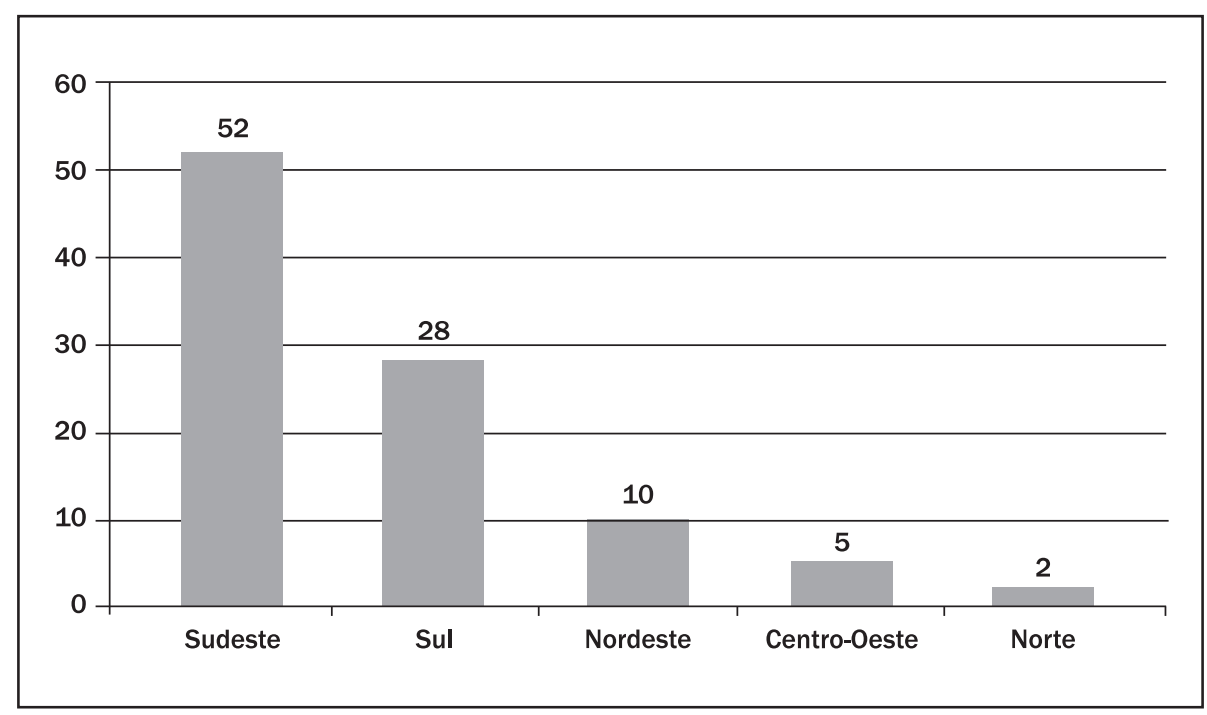

Figura 2 - Distribuição em números absolutos dos artigos considerando a procedência regional. ${ }^{10}$ Fonte: RBE-SciELO (2007-2011).

Elaboração dos autores.

Como mostram os números da Figura 2, mais da metade dos artigos publicados no período analisado, procedentes de autores vinculados a instituições acadêmicas brasileiras, advém da região Sudeste, em que pesem às iniciativas governamentais, por meio dos órgãos de fomento, incentivar a expansão e consolidação da pós-graduação de modo mais igualitário em âmbito nacional. Podemos constatar que a expansão de programas de pós-graduação no Brasil, que tem levado à gradativa desconcentração do sistema e, sobretudo, à tendência de consolidação de programas nas diferentes regiões do país, não se refletiu ainda na $R B E$. Se somarmos a região Sul com a Sudeste, teremos $83 \%$ dos artigos provenientes destas que historicamente foram protagonistas da organização e da dinamização da pós-graduação no país, particularmente no que diz respeito aos programas de doutorado. Nesse caso específico, seria interessante comparar a proveniência regional dos artigos em diferentes periódicos do estrato A1 do Qualis/CAPES/Educação para podermos ter maior clareza sobre essa relação entre a produção de pesquisa qualificada e a desigualdade regional. ${ }^{11}$

10 Os dados analisados nas Figuras 2, 3, 4, 5 e 6 excluem os artigos de procedência internacional e levam em conta a coautoria, permitindo que um mesmo artigo seja computado em duas ou mais regiões e/ou estados em razão da inserção institucional dos seus autores.

11 Sem entrar nessa análise, mas apenas identificando o lócus de editoração dos periódicos que integram o estrato A1 do Qualis/CAPES/Educação 2012, tem-se a seguinte configuração: dos 91 periódicos nesta classificação, 26 são editados no Brasil; destes, 22 na região Sudeste, 2 na região Sul, 1 na Centro-Oeste e 1 na região Nordeste. A distribuição por estado é a seguinte: 14 em São Paulo, 6 no Rio de Janeiro, 2 em Minas Gerais, 1 no Paraná, 1 no Rio Grande do Sul, 1 no Distrito Federal e 1 em Natal. 
A desigualdade, palavra que define tão bem o Brasil, revela-se também no interior das próprias regiões. Como podemos verificar na Figura 3, o estado de São Paulo detém mais da metade das publicações da região Sudeste, embora o Rio de Janeiro e Minas Gerais também tenham números expressivos de artigos publicados na $R B E$, se compararmos com os demais estados brasileiros.

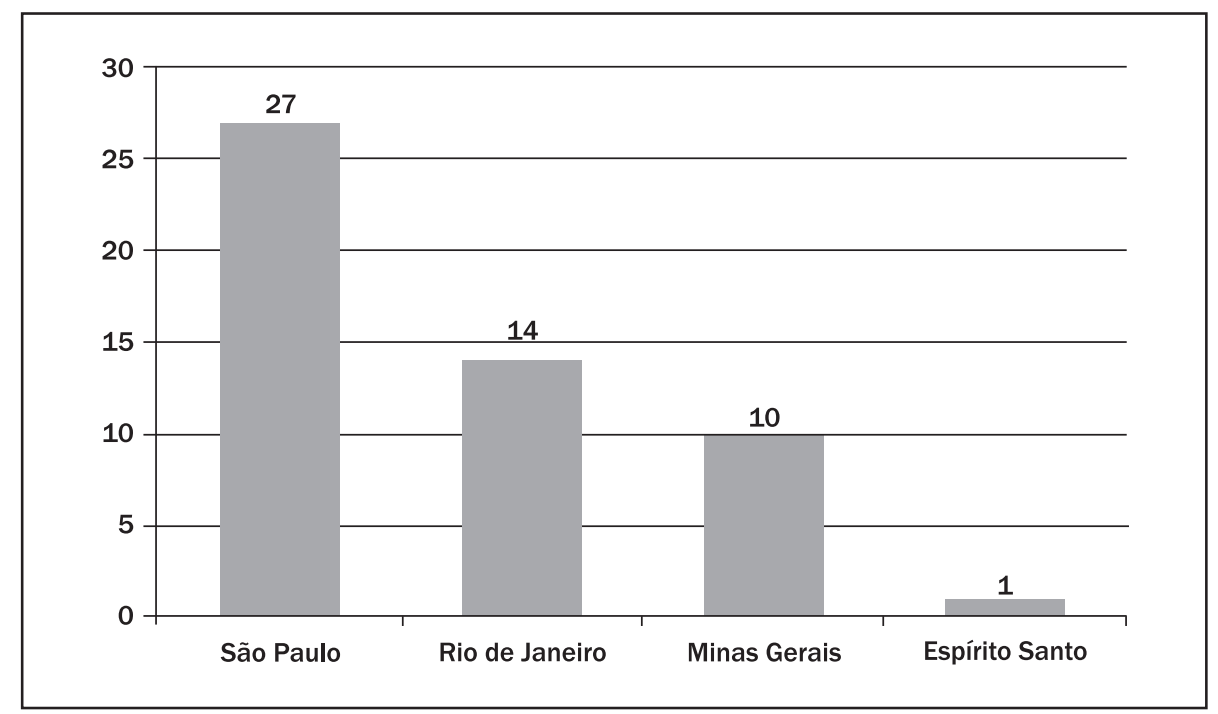

Figura 3 - Distribuição em números absolutos dos artigos entre os estados da região Sudeste. Fonte: RBE-SciELO (2007-2011).

Elaboração dos autores.

Nas regiões Sul, Centro-Oeste e Norte, verificam-se concentrações ainda maiores. O Rio Grande do Sul, o Distrito Federal e o Pará são os três estados que se destacam no âmbito das suas regiões (Figuras 4 e 5). Na região Norte, por exemplo, identificamos artigos apenas oriundos do Pará, de maneira que desconsideramos a necessidade de expor graficamente as informações dessa região. Na região Sul, cabe destacar, para além do plano regional, o Rio Grande do Sul posicionado em números absolutos como o segundo estado brasileiro com mais publicações na $R B E$ no período estudado. 


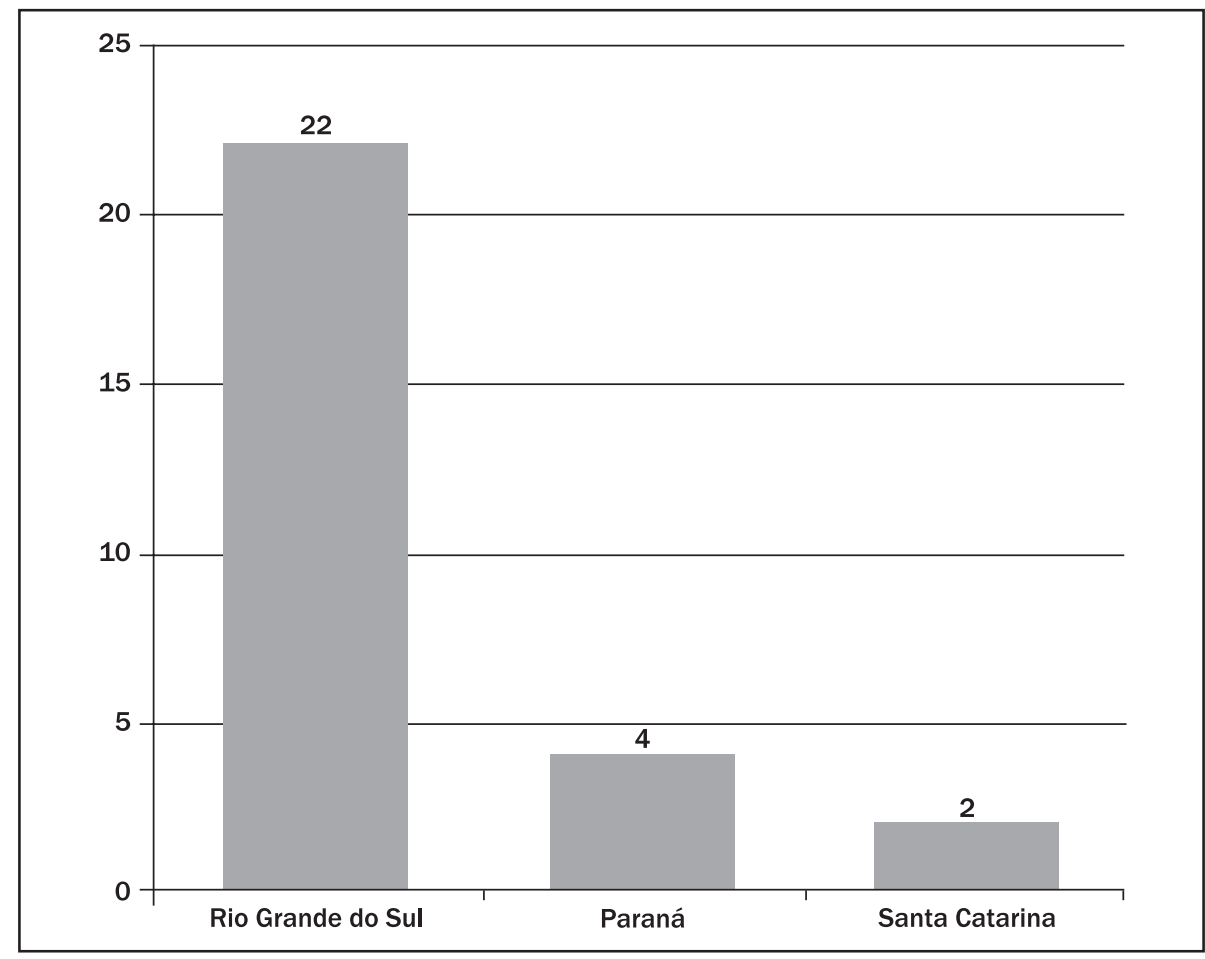

Figura 4 - Distribuição em números absolutos dos artigos entre os estados da região Sul. Fonte: RBE-SciELO (2007-2011).

Elaboração dos autores.

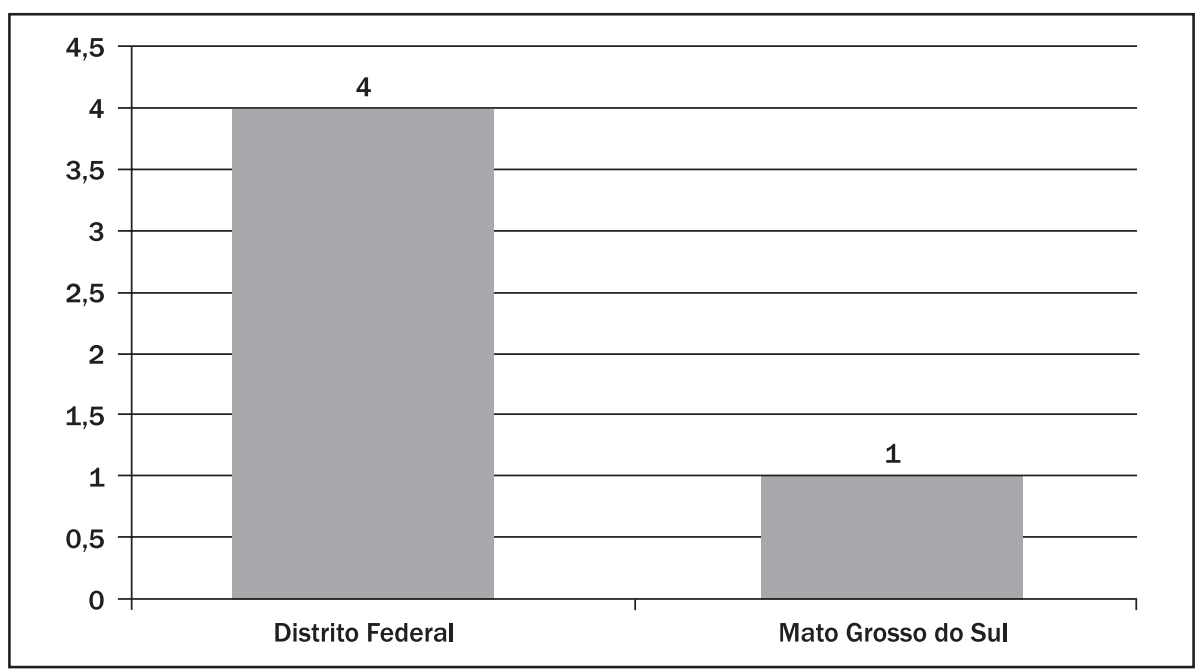

Figura 5 - Distribuição em números absolutos dos artigos entre os estados da região Centro-Oeste. Fonte: RBE-SciELO (2007-2011).

Elaboração dos autores. 
A região Nordeste (Figura 6) participa com aproximadamente 10\% dos artigos provenientes de autores vinculados a instituições acadêmicas brasileiras publicados na $R B E$ e tem uma distribuição regional mais equilibrada. Apesar da ausência de artigos provenientes de Alagoas, Maranhão e Piauí, os demais estados estão relativamente equilibrados: quatro estados na faixa dos $20 \%$ e dois com $10 \%$ dos artigos no conjunto da produção regional.

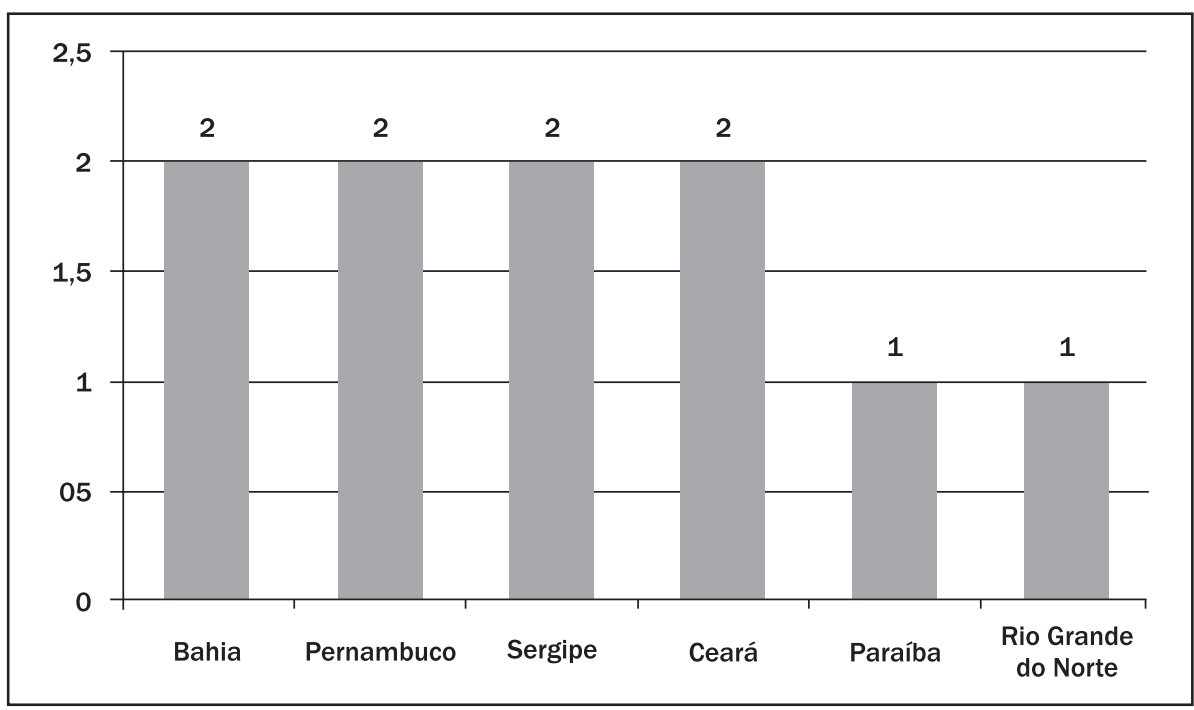

Figura 6 - Distribuição em números absolutos dos artigos entre os estados da região Nordeste. Fonte: RBE-SciELO (2007-2011).

Elaboração dos autores.

Em números absolutos, os cinco estados com mais artigos publicados são: São Paulo, com 27; Rio Grande do Sul, com 22; Rio de Janeiro, com 14; Minas Gerais, com 10 e Distrito Federal e Paraná, com quatro artigos cada um. ${ }^{12}$

No plano internacional (Figura 7), diante da tão discutida e induzida internacionalização dos periódicos acadêmicos, a $R B E$ não revela números expressivos. Em torno de $16 \%$ dos artigos publicados ao longo do período estudado são de origem estrangeira, tendo a Europa, particularmente Portugal, como lugar privilegiado de interlocução. A América do Sul conta com apenas dois artigos, revelando também uma tendência histórica de o Brasil olhar muito mais para a Europa que para o espaço latino-americano.

12 Reiteramos que foram analisados neste artigo apenas os textos presentes na seção Artigos da $R B E$, sendo assim, textos apresentados nas seções Documentos, Espaço Aberto, entre outros, não foram considerados. Entendemos que nessa seção se concentra a maioria dos textos que são derivados diretamente de pesquisas. 


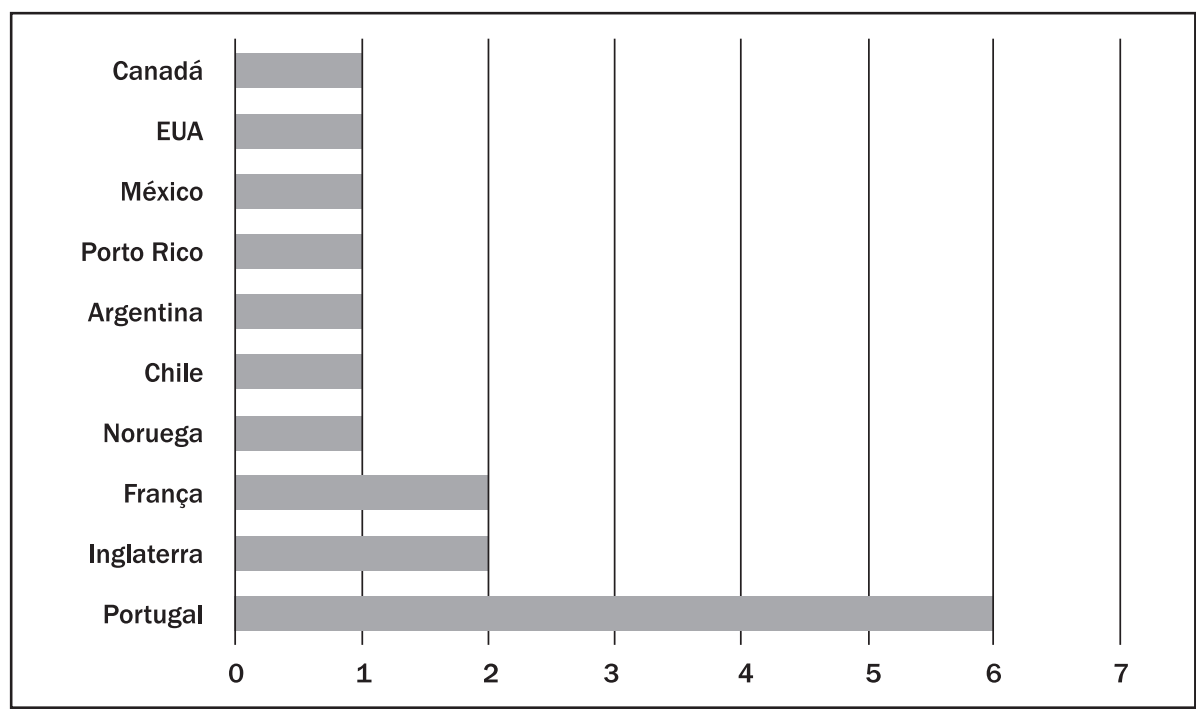

Figura 7 - Distribuição em números absolutos dos artigos considerando a proveniência internacional. Fonte: RBE-SciELO (2007-2011).

Elaboração dos autores.

No plano das concentrações institucionais, confirmamos inicialmente que os artigos publicados têm origem nos programas de pós-graduação em educação, com poucas exceções a essa regra. Verificamos também uma grande dispersão do vínculo institucional dos autores dos artigos, confirmando a expansão do sistema na última década, de modo que optamos para organizar os números apenas daquelas instituições que têm mais de um artigo publicado no período. ${ }^{13}$ Nesse sentido, dos 109 artigos publicados, considerando as 159 autorias e as cerca de 80 instituições envolvidas, apenas 23 universidades tiveram dois ou mais artigos publicados no período.

No conjunto de instituições analisadas na Figura 8, verificamos que das 13 universidades que mais publicam na $R B E, 10$ são universidades públicas, 2 são Instituição de Ensino Superior (IES) privadas e 1 é sediada em Portugal. As universidades privadas são confessionais e entre as públicas temos 3 estaduais (paulistas) e 7 federais. No conjunto das 23 IES analisadas, o número das instituições públicas sobe para 17, sendo 4 estaduais e 13 federais. Nesse universo de 23 instituições, 2 são europeias: a Universidade de Lisboa e a École des Hautes Études da França. Em números absolutos, a Universidade de São Paulo (USP) aparece com 12 publicações, a Universidade Federal do Rio Grande do Sul (UFRGS) com 10, a Universidade de Campinas (UNICAMP) com oito, a Universidade Federal do Rio de Janeiro (UFRJ) e a Universidade Federal de Minas Gerais (UFMG) com 5 artigos cada uma.

$13 \mathrm{Na}$ análise desses dados, também optamos por considerar as coautorias, computando duplamente os artigos de autores situados em diferentes instituições universitárias. 


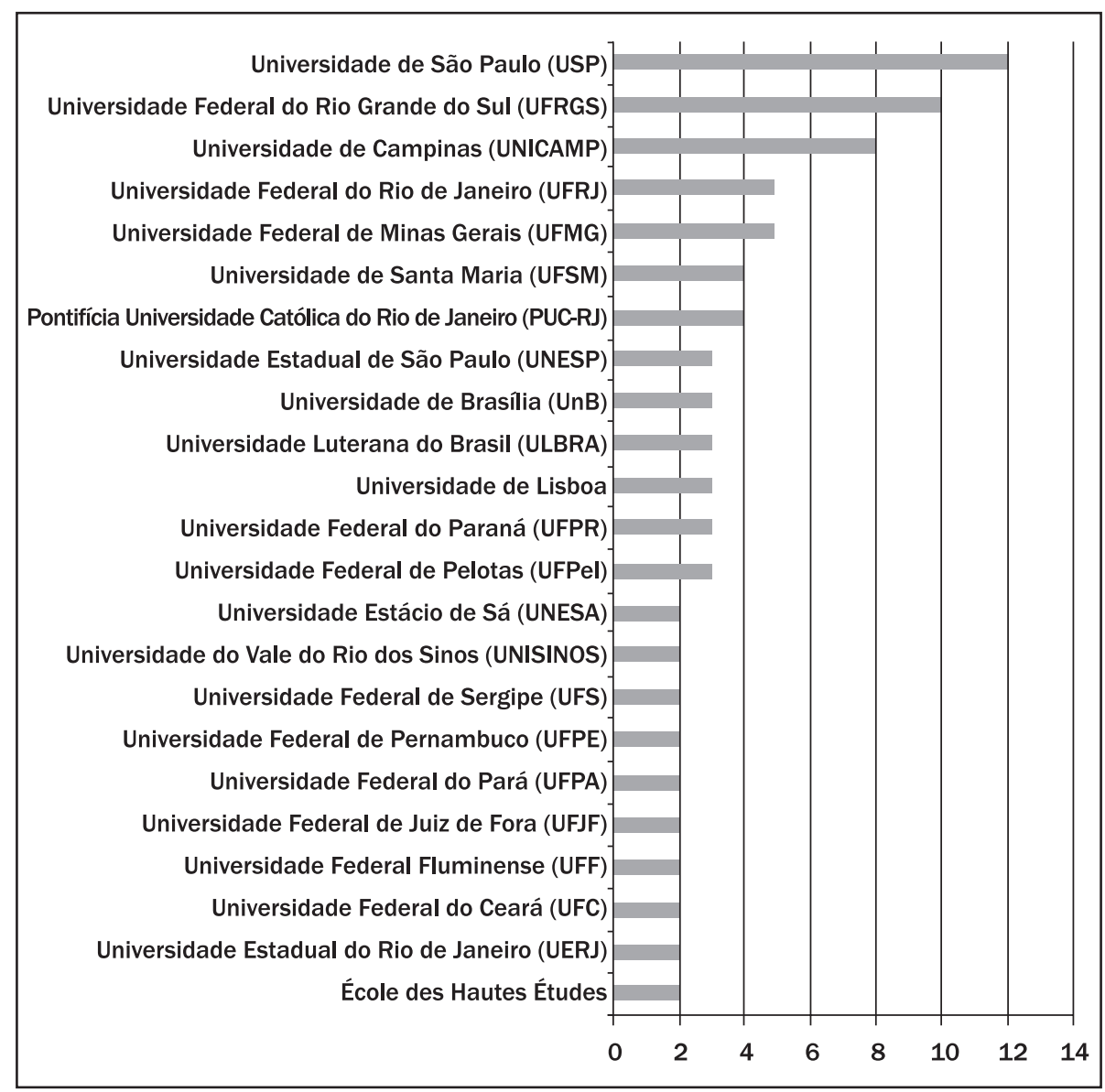

Figura 8 - Instituições em números absolutos que publicaram dois artigos ou mais na $R B E$. Fonte: RBE-SciELO (2007-2011).

Elaboração dos autores.

A última etapa dessa análise incide sobre os temas privilegiados pelos 109 artigos analisados (Figura 9). Consideramos nesse exercício de interpretação os títulos, as três palavras-chave e o resumo dos textos. Evidentemente, essa interpretação tem vieses bem definidos, de maneira que outros pesquisadores poderiam chegar a temas e, por extensão, a números diferentes. Logo, sem a pretensão de dar a palavra final nessa questão das concentrações temáticas, procuramos produzir um quadro geral que permita engendrar uma ideia do perfil dos temas privilegiados pela $R B E$.

Os balanços sobre a pesquisa educacional no Brasil, desde o ensaio seminal de Gouveia (1976), no primeiro número do Cadernos de Pesquisa, em 1976, demonstram a dispersão dos temas pesquisados na área. Logo, a produção analisada aqui reafirmou essa constatação. Nesses termos, chegamos a 20 possibilidades de categorização, embora em parte significativa dos artigos as fronteiras temáticas sejam 
muito tênues, levando o analista a decisões muitas vezes arbitrárias. ${ }^{14}$ Observamos também que alguns grupos de pesquisa mais tradicionais desenvolveram marcas identitárias mais definidas, tanto na produção dos títulos como na escolha das palavras-chave. Essas marcas facilitam a interpretação do lugar dessas produções, enquanto temáticas e grupos novos ainda carecem de um léxico compartilhado para definirem suas especificidades. Os GTs da ANPEd são, provavelmente, os marcos identitários mais fortes, tanto para o posicionamento dos autores em relação aos seus textos, como em relação aos intérpretes na produção da categorização dos artigos veiculados na $R B E$.

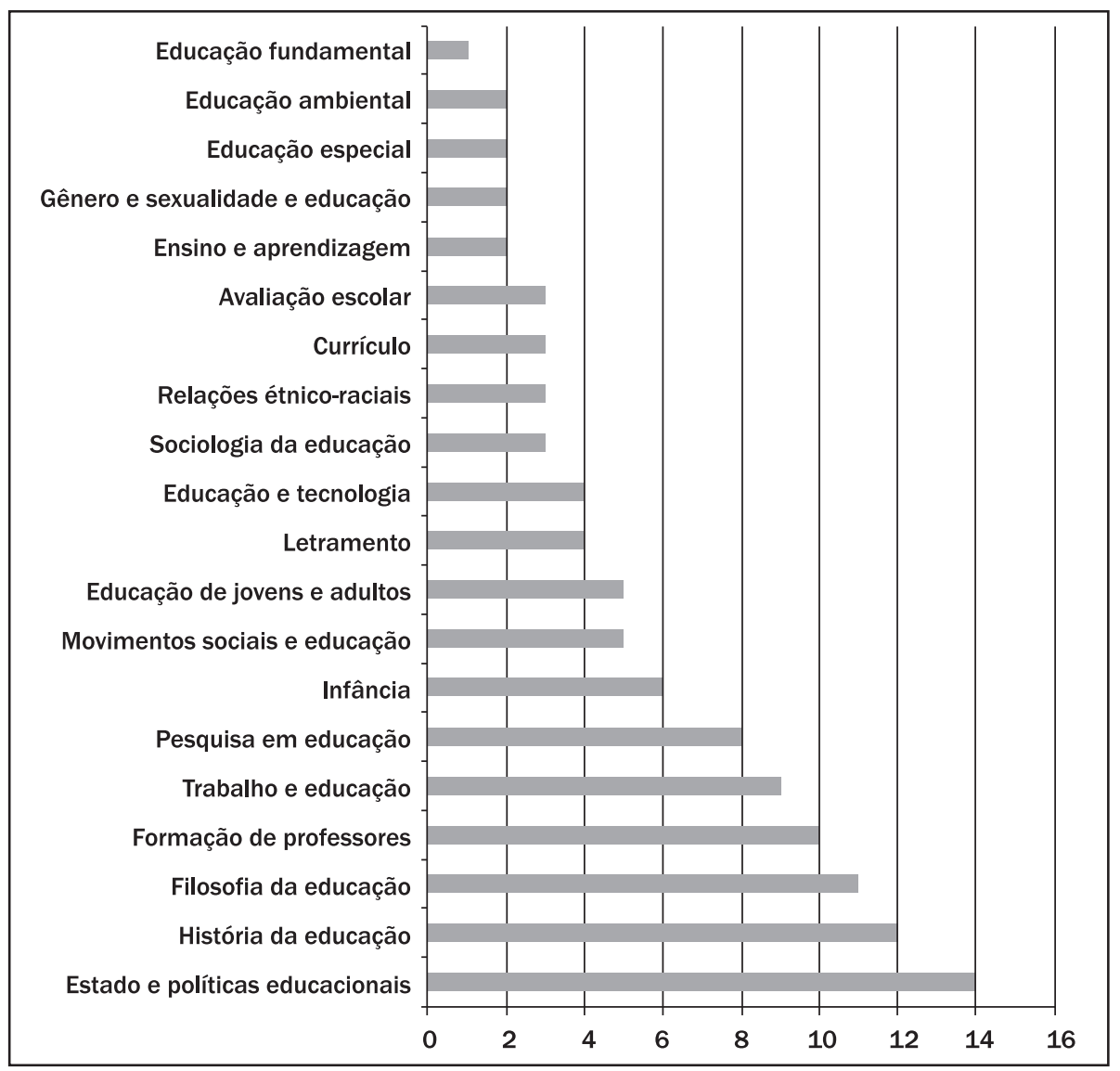

Figura 9 - Temas abordados em números absolutos considerando o título, as três palavras-chave e o resumo. Fonte: RBE-SciELO (2007-2011).

Elaboração dos autores.

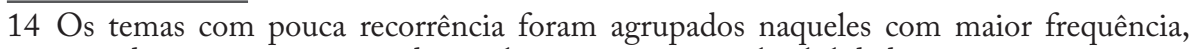
visando garantir que o quadro analítico tivesse maior legibilidade. 
A análise dos números da $R B E$ focalizados revela a consolidação de temas e áreas consagradas, tais como Estado e políticas educacionais, História da educação, Filosofia da educação, Formação de professores e Trabalho e educação. Torna explícita também a sintonia da revista com a ANPEd, na medida em que os temas privilegiados reproduzem temas tratados nos GTs, tanto dos mais tradicionais como daqueles criados mais recentemente. Por fim, cabe destacar a ênfase na discussão sobre as políticas públicas com uma característica forte do campo educacional que, para além do esforço analítico, esteve sempre engajado no plano das práticas políticas que se associam ao movimento pela melhoria da qualidade da educação no país.

\section{DADOS ILUSTRATIVOS DO ACESSO À REVISTA}

$\mathrm{O}$ acesso à $R B E$ é garantido a todos os sócios institucionais e individuais da ANPEd, por meio impresso. Também, os números da revista estão disponibilizados on-line nos portais SciELO e Redalyc, respectivamente desde 2005 e 2003, bases que divulgam dados de desempenho e evolução do periódico, alguns deles divulgados no presente artigo. Além disso, dispõe-se de 500 exemplares que são comercializados pela editora Autores Associados, o que é previsto no contrato estabelecido pela ANPEd com a referida editora.

As estatísticas disponibilizadas pelo SciELO registram um total de 2.751.003 acessos desde o ano 2005 até início de maio de 2012. Para uma visão comparativa dos acessos à $R B E$ e a outros três periódicos da área da educação disponibilizados no SciELO, ${ }^{15}$ apresentamos os resultados no Quadro 1, com indicação do ano de inserção de cada um deles no sistema. Uma comparação do total de acessos entre 2005 e 2012 indica que nesse período o número de acessos à $R B E$ se multiplicou quase 13 vezes, ao passo que para os outros três periódicos, aqui considerados para efeito de análise, o número de acessos multiplicou-se em torno de cinco vezes. Esse resultado precisa ser interpretado tendo-se em conta que em 2007 os números de acessos aos outros três periódicos eram significativamente maiores do que o de acesso à $R B E$.

15 Atualmente estão disponibilizados no SciELO um total de 12 periódicos da área da educação. No entanto, para fins de comparação, consideram-se, no Quadro 1, os periódicos que foram mencionados por Fávero e Barreiro (2007), que inclusive são os que há mais tempo estão indexados nessa base de dados. 
Quadro 1 - Número de acessos: dados comparativos no sistema SciELO

\begin{tabular}{|l|c|c|c|c|}
\hline & $\begin{array}{c}\text { Educação \& } \\
\text { Sociedade }\end{array}$ & $\begin{array}{c}\text { Educação e } \\
\text { Pesquisa }\end{array}$ & $\begin{array}{c}\text { Cadernos de } \\
\text { Pesquisa }\end{array}$ & $\begin{array}{c}\text { Revista } \\
\text { Brasileira de } \\
\text { Educação }\end{array}$ \\
\hline $\begin{array}{l}\text { Ano de entrada } \\
\text { no SciELO }\end{array}$ & 1999 & 2001 & 2003 & 2005 \\
\hline $\begin{array}{l}\text { Total de acessos } \\
\text { ao SciELO, 2007 }\end{array}$ & 2.585 .397 & 948.263 & 802.703 & 214.092 \\
\hline $\begin{array}{l}\text { Total de acessos ao } \\
\text { SciELO, 2012 }\end{array}$ & 9.851 .731 & 3.650 .392 & 3.822 .376 & 2.751 .003 \\
\hline
\end{tabular}

Fonte: SciELO, 2012.

Elaboração dos autores.

A Redalyc disponibiliza o número de consultas à revista realizadas no México e por grupos de países, que ilustram sua circulação em âmbito internacional, destacando-se nesse levantamento o seu acesso em países da América Latina e Caribe.

\section{Quadro 2 - Consulta à $R B E$ no México e por grupo de países no período 2007-2011}

\begin{tabular}{|l|r|}
\hline México e grupo de países & \multicolumn{1}{|c|}{ Total de consultas } \\
\hline ALyC & 439.162 .0 \\
\hline México & 11.027 .0 \\
\hline Indefinido* & 185.601 .0 \\
\hline Ásia & 4.576 .0 \\
\hline EUyC & 34.978 .0 \\
\hline África & 1.981 .0 \\
\hline Europa & 27.093 .0 \\
\hline Oceania & 31.0 \\
\hline
\end{tabular}

Fonte: Redalyc, 2012.

* Essa informação é reproduzida tal como apresentada no levantamento disponibilizado pela Redalyc, ou seja, não é identificado à qual país ou grupo de países esse número se refere.

Elaboração dos autores.

Na plataforma SciELO, a consulta aos dez artigos mais acessados no período de 2007 a 2011 evidencia concentração em seis temas, tal como retratado na Figura 10. Entre esses dez artigos estão incluídos três que versam sobre letramento e dois são relativos à universidade. Artigo que trata de inclusão escolar foi o mais acessado. 


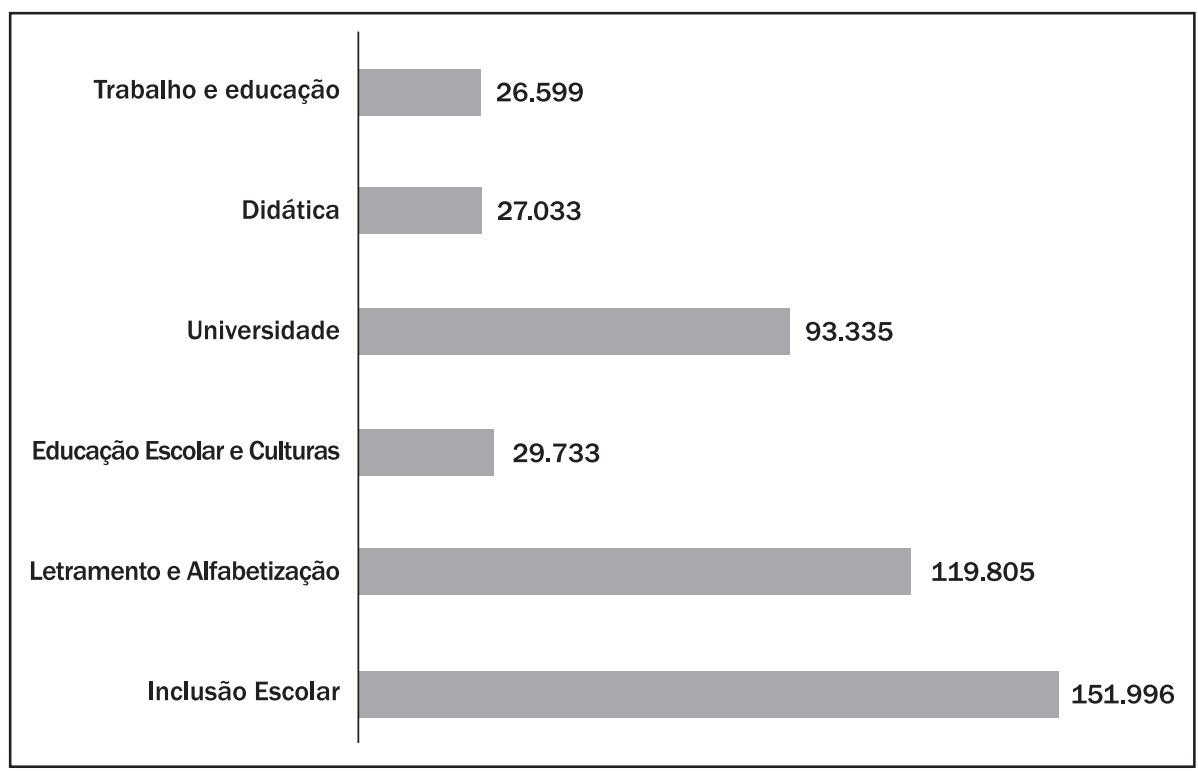

Figura 10 - Temas abordados nos dez artigos mais acessados na plataforma SciELO. Fonte: SciELO, 2012.

Elaboração dos autores.

Se compararmos os dados referentes aos dez artigos mais acessados com os dados apresentados anteriormente sobre os temas privilegiados na $R B E$, nos números analisados, perceberemos que temas que não revelam concentrações significativas, tais como letramento e educação especial (inclusão), são aqueles tratados pelos artigos mais acessados.

O SciELO disponibiliza cálculo do fator de impacto (FI) dos periódicos indexados. O FI, índice que expressa o número médio de citações que um periódico recebeu nos últimos dois ou três anos no interior de uma base de indexação, tornou-se para muitas áreas do conhecimento o valor principal para medir a qualidade dos periódicos. Em outros termos, a qualidade é mensurada pela penetração do periódico no debate científico em nível internacional, considerando, na linguagem corrente entre os editores de periódicos acadêmicos, a visibilidade dos artigos e da revista. $\mathrm{Na}$ grande área da ciências humanas, e especialmente na área da educação, esse índice não tem sido considerado ou tem o seu peso relativizado por outros critérios de avaliação. Essa opção, longe de revelar a inconsistência científica da área, mostra a especificidade dos diversos campos do conhecimento. Entre essas diferenças, poderíamos destacar que o uso dos periódicos como fonte de pesquisa tem crescido na área da educação, contudo estes estão longe de representar a fonte de consulta privilegiada. Os livros, os capítulos, as teses, as monografias permanecem com significativa presença na sustentação das pesquisas na área. Uma segunda questão, que envolve um grau ainda maior de complexidade, é a relação entre o FI e o processo de internacionalização da ciência. Esse processo não implica apenas 
em ritmos diferenciados de inserção internacional entre as diferentes áreas do conhecimento, mas sim pesos e modos distintos de se relacionar com a produção produzida fora do país. Logo, consideramos esse índice importante, porém não definitivo ou absoluto para avaliar os periódicos da área.

Para aquilatar-se o FI obtido pela $R B E$, tomam-se como referência os resultados obtidos pelos periódicos da área da educação que são referenciados neste artigo pela sua tradição, cujos dados são apresentados no Quadro 3.

Quadro 3 - Periódicos e fator de impacto nos últimos três anos (ano base 2011)

\begin{tabular}{|l|c|}
\hline \multicolumn{1}{|c|}{ Título do periódico } & Fator de impacto \\
\hline Educação É Sociedade (UNICAMP-CEDES) & 0.2687 \\
\hline Revista Brasileira de Educação (ANPEd) & 0.2593 \\
\hline Cadernos de Pesquisa (FCC) & 0.1491 \\
\hline Educação e Pesquisa (USP) & 0.0541 \\
\hline
\end{tabular}

Fonte: SciELO, 2012.

Elaboração dos autores.

No que tange especificamente às citações recebidas pela $R B E$, destacamos, conforme o Quadro 4, uma tendência crescente de inserção da $R B E$ nas publicações acadêmicas da área. De 83 citações em 2007, a $R B E$ passou a 193 em 2011, mostrando um crescimento contínuo e sustentado ao longo do período.

\section{Quadro 4 - Números de artigos por fascículo, citações concedidas e recebidas pela $R B E$}

\begin{tabular}{|c|c|c|c|}
\hline $\begin{array}{c}\text { Revista Brasileira de } \\
\text { Educação }\end{array}$ & $\begin{array}{c}\text { Média de artigos por } \\
\text { fascículo }\end{array}$ & $\begin{array}{c}\text { Número de citações } \\
\text { concedidas }\end{array}$ & $\begin{array}{c}\text { Número de citações } \\
\text { recebidas }\end{array}$ \\
\hline 2011 & 10,67 & 931 & 193 \\
\hline 2010 & 12,00 & 980 & 158 \\
\hline 2009 & 12,33 & 1.084 & 129 \\
\hline 2008 & 11,67 & 1.131 & 105 \\
\hline 2007 & 11,00 & 1.002 & 83 \\
\hline
\end{tabular}

Fonte: SciELO, 2012.

Elaboração dos autores.

Alerta-se que as informações aqui registradas visam ilustrar o desempenho da revista. No entanto, não apoiam análises conclusivas, o que demandaria um exame detalhado dos dados, em perspectiva histórica e comparativa com outros periódicos, levando-se em conta diversas variáveis, entre elas o período de inserção nas bases de dados, o número de fascículos e artigos publicados, entre outras, propósito que extrapola os limites do presente mapeamento. 


\section{DESAFIOS E PERSPECTIVAS}

Tão importante quanto a produção de conhecimento é a sua divulgação. Esse reconhecimento tem impulsionado iniciativas de qualificação dos periódicos na área da educação, em cujo movimento se inserem os esforços da ANPEd, em particular com a avaliação por pares dos periódicos da área da educação, que tem assumido um caráter formativo, e recentemente com a criação do Fórum de Editores de Periódicos da Área da Educação.

Quanto à $R B E$, sob sua responsabilidade, este breve estudo traz evidências que permitem afirmar que o periódico tem exercido importante papel enquanto veículo de divulgação dos estudos e pesquisas educacionais. É possível afirmar que a $R B E$ vem atendendo aos aspectos formais de qualidade, como normalização, periodicidade, circulação, aliados a sua indexação em várias bases de dados. Em especial, a disponibilização no SciELO e Redalyc possibilita sua ampla circulação. O criterioso processo de produção da revista, desde a submissão do artigo por parte do autor, sua avaliação, até a eventual publicação, tem garantido a qualidade de seu conteúdo, representativo da produção da área da educação.

Os desafios que se colocam aos periódicos brasileiros apresentam-se com nuances diferenciadas em cada área do conhecimento, decorrentes de suas características e trajetórias. $\mathrm{Na}$ área da educação há limitações de editoração que precisam ser superadas, que se situam em um continuum que abarca desde condições de infraestrutura de produção até viabilização de sua presença em âmbito internacional.

No caso da $R B E$, além do aprimoramento das condições operacionais do processo editorial, viabilizadoras inclusive do aumento do número de fascículos editados por ano, impõem-se como necessárias iniciativas que garantam o contínuo aperfeiçoamento da qualidade e da ampliação de sua disseminação, sobretudo no contexto internacional. Para além da presença de autores internacionais nos artigos divulgados, parece-nos inadiável a publicação multilíngue de todos ou de parte dos artigos, em português e inglês, língua franca na comunicação científica.

Essa perspectiva não se coloca em virtude de rankings internacionais de indexação, mas sim com o propósito de propiciar, por meio das publicações, a inserção do conhecimento produzido no Brasil em âmbito internacional, intensificando o diálogo como meio de enriquecer a pesquisa da área. $\mathrm{O}$ movimento a ser feito é o de reconhecimento das peculiaridades da área da educação e a atenção às iniciativas que vêm sendo implementadas pelos periódicos científicos brasileiros, bem como de outros países, das diversas áreas.

Em recente artigo que analisa os periódicos brasileiros e a comunicação da pesquisa nacional, Packer aponta quatro linhas de ação com vistas ao avanço da qualidade e do desempenho dos periódicos. Julgamos oportuna sua reprodução neste artigo, pois esboçam perspectivas que merecem ser debatidas. São elas:

- O aprimoramento da publicação, indexação, interoperação e avaliação dos periódicos de qualidade por meio do desenvolvimento e fortalecimento do Programa SciELO pari passu com o estado da arte internacional de publica- 
ção científica. Espera-se que o SciELO exerça mais funções de metapublisher na avaliação das estruturas e dos processos de editoração dos periódicos indexados com base em indicadores de profissionalização e internacionalização.

- Ampliação e intensificação dos programas, eventos, ações e infraestruturas relacionados com a capacitação dos editores, editores associados, revisores e autores no estado da arte em comunicação científica, com a participação da ABEC e do IBICT, em cooperação com as sociedades científicas e órgãos representativos da comunicação científica internacional.

- Fortalecimento do Programa Qualis com avaliação enriquecida com uso de múltiplas medidas de desempenho e de fontes de indexação. A adoção dos indicadores deve levar em conta os fatores que influenciam o número de citações recebidas pelos artigos e periódicos. Espera-se uma política de valorização dos periódicos brasileiros que privilegie os avanços no desempenho internacional.

- Ampliação do escopo do Programa de Apoio à Editoração e Publicação Científica do CNPq e CAPES com aumento substancial de recursos para financiar projetos de médio e longo prazo orientados à renovação das estruturas e processos de editoração com resultados almejados, além da manutenção da publicação dos periódicos. Nesse movimento, é esperada a convergência dos programas de apoio aos periódicos das FAPs e das universidades. (2011, p. 77)

Encerramos este texto propondo que esses aspectos, que abrangem questões fulcrais relativas à qualidade e à divulgação do conhecimento por meio de periódicos científicos e remetem desde iniciativas internas à gestão dos periódicos até políticas públicas que incidem em sua produção, se constituam em uma pauta de debates na área da educação.

\section{REFERÊNCIAS}

FÁvero, Osmar; Barreiros, Débora. A comunicação das pesquisas na área de educação: o papel da Revista Brasileira de Educação na difusão do conhecimento. In: Pimentel, Marília Araújo Lima (Org.). Memórias da ANPEd. 30 anos. Rio de Janeiro: ANPEd, 2007. 1 CD-ROM.

Ferraro, Alceu Ravanello. A ANPEd, a pós-graduação, a pesquisa e a veiculação da produção intelectual na área da educação. Revista Brasileira de Educação, Rio de Janeiro, ANPEd; Campinas, Autores Associados, n. 30, número especial, p. 47-69, set./dez. 2005. Gouveia, Aparecida Joly. Pesquisa em educação no Brasil: de 1970 para cá. Cadernos de Pesquisa, São Paulo, Fundação Carlos Chagas, n.19, p. 75-79, 1976.

PAcker, Abel Laerte. Os periódicos brasileiros e a comunicação da pesquisa nacional. Revista USP, São Paulo, n. 89, p. 62-77, maio 2011. Disponível em: <http://www. revistasusp.sibi.usp.br/scielo.php?.pid=S0103-99892011000200004\&script=sci_ abstract>. Acesso em: 12 maio 2012. 
REVISTA BRAsileIRA DE EDUCAÇÃo. Rio de Janeiro: ANPEd; Campinas: Autores Associados, n. 34-48, 2007-2011. Disponível em: <http://www.scielo.br/scielo. php?script=sci_serial\&pid=1413-2478\&lng=pt\&nrm=iso >. Acesso em: 7 maio 2012. Revista BRAsileira DE EDUCAÇÃo. Rio de Janeiro: ANPEd; Campinas: Autores Associados. 2012. Disponível em: <http://www.redalyc.org/src/inicio/Indicador. jsp?tipoGrafica=31_275r\&revista=Revista Brasileira de Educa\{ccedil\}\{atilde\}o 16(48)\&anio=2011>. Acesso em: 9 maio 2012.

SCIENTIFIC ELECTRONIC LibRaRY ONLINE (SciELO). 2012. Disponível em: <http:// statbiblio.scielo.org/stat_biblio/index.php?lang=pt\&country=scl\&issn=>. Acesso em: 7 maio 2012.

Strehl, Letícia. O fator de impacto do ISI e a avaliação da produção científica: aspectos conceituais e metodológicos. Ciência da Informação, Brasília, v. 34, n. 1, p. 19-27, jan./ abr. 2005. Disponível em: <http://www.scielo.br/pdf/ci/v34n1/a03v34n1.pdf>. Acesso em: 9 maio 2012.

Thomaz, Petronio Generoso; Assad, Renato Samy; Moreira, Luiz Felipe Pinto. Uso do fator de impacto e do índice $\mathrm{H}$ para avaliar pesquisadores e publicações. Arquivos Brasileiros de Cardiologia, Rio de Janeiro, SBC, v. 96, n. 2, p. 90-93, 2011. Disponível em: <http://biblioteca.unipac.br/cgi-bin/wxis.exe?IsisScript=ph18/003.xis\&cipar=jf/phl. cip\&bool=exp\&opc=decorado\&exp=FATOR\%20DE\%20IMPACTO\&code=\&lang=> . Acesso em: 9 maio 2012.

\section{SOBRE OS AUTORES}

Carlos Eduardo Vieira é doutor em história e filosofia da educação pela Pontifícia Universidade Católica de São Paulo (PUC-SP). Professor associado da Universidade Federal do Paraná (UFPR).

E-mail: cevieira9@gmail.com

Sandra Zákia Sousa é doutora em educação pela Universidade de São Paulo (USP). Professora da mesma instituição e da Universidade Cidade de São Paulo (UNICID).

E-mail: sanzakia@usp.br 